\title{
AMERICA
}

\section{ON THE ICE}

\section{Antarctic Policy Issues}

\author{
Frank G. Klotz \\ 1990
}

\author{
National Defense University Press

RO Fort Lesley J. Mc Nair
PRESS
Washington, DC

